\title{
PASTOREIO DE CURTA DURAÇÃO COM OVINOS EM CAATINGA RALEADA NO SERTÃO CEARENSE ${ }^{1}$
}

\author{
NILZEMARY LIMA DA SILVA², JOÃO AMBRÓSIO DEARAÚJO FILHO³, \\ FRANCISCO BENI DE SOUSA e MARCELO RENATO ALVES DEARAÚJO²
}

\begin{abstract}
RESUMO - A pesquisa foi conduzida em Sobral, Ceará, no período de janeiro de 1992 a julho de 1994 e objetivou determinar o desempenho produtivo de ovinos, produção de forragem e características fitossociológicas do estrato herbáceo da caatinga raleada submetida à adubação orgânica e pastoreio de curta duração, com duas taxas de lotação. Foram testadas as cargas de 3,3 (leve) e 10 cab/ha (pesada), com (5 t/ha de esterco de caprinos) e sem adubação orgânica. Utilizou-se um delineamento inteiramente casualizado distribuído em um fatorial 2 × 2 × 3 (carga animal x adubação x ano), com duas repetições. $\mathrm{O}$ pastejo de ovinos resultou no desaparecimento total das gramíneas e no aumento das dicotiledôneas herbáceas no período estudado. A adubação orgânica não mostrou efeitos significantes $(\mathrm{P}>0,05)$ quanto à performance animal e das pastagens. $\mathrm{O}$ melhor desempenho animal $(\mathrm{P}<0,01)$ foi obtido nas parcelas com carga leve (3,3 cab/ha), com 108,0 g/cab/dia e o da pastagem foi observado nas áreas com carga pesada (10 cab/ha) com 71,2 kg/ha/ano. Apesar da elevada produção animal, o pastejo de curta duração, somente com ovinos, não deve ser recomendado para a caatinga raleada, por desestabilizar a composição do estrato herbáceo, principal componente da dieta desses ruminantes. Provavelmente, a alternância com outro herbívoro de hábito de pastejo e preferência alimentar diferente resultará em uma melhor sustentabilidade da exploração.
\end{abstract}

Termos para indexação: adubação, carga animal, ganho de peso, semi-árido.

\section{SHORT DURATION GRAZING WITH SHEEP ON A THINNED CAATTINGA IN THE SERTÃO OF CEARÁ}

\begin{abstract}
The experiment was carried out in Sobral, Ceará, Brazil, from January 1992 to July 1994, with the objective of determining the productive performance of lambs, forage production, and frequency of the species of the herbaceous layer of a thinned caatinga, under organic fertilization and short duration grazing, with two stocking rates. The stocking rates were 3.3 (light) and 10.0 heads/ha (heavy), with ( 5.0 ton/ha of goat manure) and without fertilization. A complete randomized design was followed, with a factorial distribution of $2 \times 2 \times 3$ (stocking rate $\times$ fertilization $\times$ year), with two repetitions. Sheep grazing resulted in total disapearing of the grass species and an increasing of the forbs, along the period of study. The organic fertilization did not show significant effects $(\mathrm{P}>0.05)$ on the animal and pasture performances. The best animal performance $(\mathrm{P}<0.01)$ was observed on the padocks under light stocking rate $(3.3 \mathrm{head} / \mathrm{ha})$, with $108.0 \mathrm{~g} / \mathrm{head} / \mathrm{day}$, and the best performance $(\mathrm{P}<0.01)$ of the pasture was obtained on the areas under heavy stocking rate $(10 \mathrm{head} / \mathrm{ha})$, with $71.2 \mathrm{~kg} / \mathrm{ha} /$ year. Although, the short duration grazing with sheep presented high performance by the animals and by the pasture, it should not be recommended for the thinned caatinga, because it unbalances the herbaceous layer composition, the principal source of the diet of those ruminants. Possibly, the alternate grazing with other herbivorous of different grazing habit and diet composition may result on a beter sustainability of the exploration.
\end{abstract}

Index terms: fertilization, semi-arid, stocking rate, weight gain.

\footnotetext{
${ }^{1}$ Aceito para publicação em 22 de junho de 1998.

${ }^{2}$ Eng. Agr., M.Sc., Embrapa-Centro Nacional de Pesquisa de Caprino (CNPC), Caixa Postal D-10, CEP 62011-970 Sobral, CE. E-mail: nmary@cnpc.embrapa.br

${ }^{3}$ Eng. Agr., Ph.D, Embrapa-CNPC.
}

\section{INTRODUÇÃO}

O objetivo principal das práticas de manejo das pastagens é maximizar a produção animal por unidade de área, mantendo sua produtividade de forragem (Heitschmidt \& Walker, 1983). 
Os sistemas de pastoreio têm sido desenvolvidos para aumentar a produtividade animal da pastagem mediante aumento da capacidade de suporte. Heitschmidt et al. (1982) descreveram três meios de se incrementar a capacidade de suporte: melhorando a qualidade e aumentando a quantidade de forragem e incrementando a eficiência de uso.

O pastoreio de curta duração é um sistema intensivo, rotacional, o qual usa períodos relativamente curtos de pastejo, separados por período de repouso prolongado e alta carga animal para manipular a pressão de pastejo, a utilização de forragem e, conseqüentemente a produção de forragem e do rebanho (Ralphs et al., 1984, citados por Weigel et al., 1989). Entre as vantagens que o pastoreio de curta duração traz, citam-se: aumento da capacidade de suporte, melhoria no desempenho individual dos animais e aumento da qualidade da forragem.

Durante o período chuvoso, as forrageiras anuais dominantes na vegetação herbácea da caatinga, além de apresentarem um crescimento rápido, diferenciam-se pela duração de seu ciclo fenológico, o que resulta em uma forte periodicidade e excesso de forragem no período. O sistema de pastoreio contínuo, comum na região, não sintoniza com o ritmo crescente de oferta de forragem, resultando em perdas quantitativas e qualitativas consideráveis. O pastoreio de curta duração, dada a sua dinâmica oriunda das características de rotação dos pastos, poderá ser uma alternativa ao manejo racional das pastagens nativas na região da caatinga.

Os resultados de pesquisa relatados por Oliveira et al. (1986) demonstraram que borregos da raça Santa Inês, recebendo suplementação a pasto durante a época de carência alimentar, ganharam $42 \mathrm{~g} /$ animal/dia em pastagem nativa. Segundo Leite et al. (1995) a produção de peso vivo ( $\mathrm{kg} / \mathrm{ha} / \mathrm{ano})$ foi de 18,8 em ovinos em caatinga rebaixada.

O pastejo por ovinos afetou a composição botânica do estrato herbáceo, pela queda na freqüência das gramíneas de alto valor forrageiro e aumento daquelas de baixo valor forrageiro, e favoreceu as dicotiledôneas (Pereira Filho, 1995).

Por sua vez, em grandes áreas da caatinga, os solos já se encontram aparentemente exauridos, o que se reflete principalmente em alterações na composição florística da vegetação anual. Os maiores benefícios da fertilização de pastagens nativas centralizam-se sobre uma maior produção de forragem, maior produção de sementes, elevação das qualidades nutritivas da forragem e no favorecimento ao estabelecimento de plântulas (Andrease, 1971). Segundo Silva (1992) a adubação fosfatada pode ser utilizada como um importante veículo na recuperação de pastagens nativas degradadas, devido à sua capacidade de provocar profundas modificações na composição florística do estrato herbáceo, elevando a participação de espécies mais palatáveis e diminuindo, conseqüentemente, a de espécies não forrageiras ou forrageiras de baixa palatabilidade.

A presente pesquisa objetivou determinar o desempenho produtivo de ovinos, quando submetidos ao pastoreio de curta duração, bem como avaliar os efeitos do pastejo sobre as características fitossociológicas e os efeitos da adubação orgânica sobre a produção da forragem.

\section{MATERIAL E MÉTODOS}

A pesquisa foi conduzida na Fazenda Experimental Crioula, pertencente à Embrapa-Centro Nacional de Pesquisa de Caprinos, em Sobral, CE, localizada a $3^{\circ} 4^{\prime}$ de latitude sul e $40^{\circ} 21^{\prime}$ de longitude oeste, numa altitude de 83 m (Relatório... 1986), no período de 1992-1994. Os solos são do tipo Bruno não-cálcico e litólico, cobertos por uma vegetação de caatinga sucessional, hiperxerófila, com árvores de porte pequeno a médio. Segundo a classificação climática de Köppen, a região possui um clima do tipo AW de savana (Miller, 1971) caracterizado por uma estação seca que vai de julho a dezembro e uma chuvosa de janeiro a junho, com uma precipitação média de $758,8 \mathrm{~mm}$. Durante os três anos de execução da pesquisa, os totais de precipitações observados foram de $432,0 \mathrm{~mm}, 466,5 \mathrm{~mm}$ e $1449,5 \mathrm{~mm}$, respectivamente para os anos de 1992, $1993 \mathrm{e}$ 1994. A área total do experimento foi de 3,2 ha, dividida em oito piquetes de 0,3 ha e oito de 0,1 ha cada, para as cargas leve $(0,3 \mathrm{ha} / \mathrm{cab}$.) e pesada $(0,1 \mathrm{ha} / \mathrm{cab}$.). Foram testados os seguintes tratamentos: carga animal leve com adubação (CLA), carga animal leve sem adubação (CLNA), carga animal pesada com adubação (CPA) e carga animal pesada sem adubação (CPNA). Os animais utilizados foram ovinos, machos, mestiços, castrados, recém-desmamados. A adubação orgânica (5 t/ha de esterco de caprino) foi feita no início do período chuvoso. Os animais eram admitidos na pastagem, quando a mesma apresentava condições de pastejo, na época chuvosa e pesados antes de 
entrar nos piquetes e a cada 14 dias. O período de ocupação dos piquetes foi de sete dias, com 21 dias de repouso e a duração do período anual de pastejo de 80 dias, aproximadamente. Utilizou-se um delineamento inteiramente casualizado distribuído em um fatorial $2 \times 2 \times 3$ (carga animal $\mathrm{x}$ adubação $\mathrm{x}$ ano), com duas repetições.

As variáveis avaliadas foram: freqüência das espécies herbáceas, produção de fitomassa e ganho de peso dos animais. A unidade amostral para medir os componentes do estrato herbáceo, consistia de uma moldura de ferro chato com dimensões de $1,00 \times 0,25 \mathrm{~m}$ (Araújo Filho et al., 1986). Foram coletadas 100 amostras por piquete para determinação da freqüência das espécies e cobertura do solo. A freqüência foi determinada anotando-se a presença de cada espécie na unidade amostral, sendo expressa como a percentagem de parcelas amostrais em que a espécie ocorreu (Cox, 1967). A produção de fitomasssa do estrato herbáceo foi obtida por meio direto (corte e pesagem), separando-se, no campo, os componentes gramíneas e dicotiledôneas. As amostras para determinação da freqüência e da produção de fitomassa foram tomadas uma vez por ano em cada piquete, antes da admissão dos animais.

\section{RESULTADOS E DISCUSSÃO}

A Tabela 1 sumaria as variações das freqüências das espécies herbáceas mais comuns nas parcelas do experimento, durante o período de realização da pesquisa. As gramíneas, de um modo geral, tiveram suas freqüências reduzidas em todos os tratamentos, ao final do período do experimento. Assim, a milhã-branca (Brachiaria plantaginea) e o capim-barba-de-bode (Cyperus compressus) praticamente desapareceram das parcelas, independentemente do tratamento. O capim-rabo-de-raposa (Setaria sensitiva) não foi detectado em nenhum período nas áreas submetidas à carga pesada, mas apresentou uma freqüência média no início e baixa no final, nas áreas sob pastoreio leve.

O feijão-de-rola (Phaseolus lathiroides) e o mata-pasto (Senna obtusifolia) tiveram os maiores valores de freqüência entre as leguminosas, apresentando variações relativamente pequenas e sem tendências definidas. Por sua vez, o amendoim-bravo (Arachis pusilla) e a malícia (Mimosa sensitiva) desapareceram das áreas sob carga pesada, sofrendo, no entanto, menores reduções da ocorrência nas parcelas sob carga leve.
O bamburral (Hyptis suaveolens) foi, entre as dicotiledôneas herbáceas, a única que teve sua freqüência substancialmente aumentada em todas as parcelas experimentais, ao longo do período (Tabela 1). A jitirana-lisa (Ipomea sp.) e a jitirana-peluda (Merrenia aegyptia), ambas com elevada freqüência no início dos trabalhos, tenderam a diminuir. $\mathrm{O}$ azedinho (Oxalis sp.), o bredo (Amaranthus viridis), o evolvulo (Poligola sp.) e o manda-pulão (Croton sp.) desapareceram das parcelas experimentais, enquanto o paco-paco (Wissadula spicata) manteve sua presença nos piquetes sob carga pesada e teve sua freqüência nula nas àreas sob carga leve.

A disponibilidade de fitomassa de pé (Tabela 2) aumentou de 2.407,3 kg/ha em 1992 para $4.085,00 \mathrm{~kg} / \mathrm{ha}$ em 1994, ou seja, $69,7 \%$, provavelmente em virtude das melhores condições de pluviosidade verificadas no último ano. $\mathrm{O}$ incremento de produção causada pela adubação orgânica foi de 33,2\% no ano de 1992, e de 28,3\% em 1994.

As gramíneas, como um grupo, iniciaram o período (1992) com $28 \%$ de participação na composição florística da fitomassa das parcelas adubadas e 14,5\% nas não adubadas. Ao final (1994), no entanto, sua participação era nula.

Os resultados indicam que nenhum dos tratamentos afetou a disponibilidade de fitomassa, sendo as variações, ao longo do período, relacionadas com as flutuações das precipitações pluviais. No entanto, foram observadas profundas modificações na freqüência das espécies e na composição florística, não em razão dos tratamentos ou do clima, mas do pastejo dos ovinos. Algumas dicotiledôneas herbáceas e todas as espécies de gramíneas desapareceram totalmente das parcelas experimentais. Os estudos de composição da dieta de ovinos (Nascimento, 1988) mostraram que as gramíneas são os componentes mais importantes e tendem a desaparecer da pastagem continuamente utilizada por esses animais. Os resultados do presente trabalho confirmam tais afirmações.

A Fig. 1 mostra que o desenvolvimento ponderal dos ovinos foi geralmente crescente, houve, porém, em alguns tratamentos, tendência de estabilização ao fim do período. Vale salientar que, no primeiro ano e nos dois terços iniciais do segundo ano, o ganho de peso dos animais foi semelhante em ambas as 
taxas de lotação. Porém, as diferenças se acentuaram no restante do período experimental, provavelmente em virtude do desaparecimento das gramíneas, prin- cipal componente da dieta de ovinos.

A Tabela 3 sumaria o desempenho dos animais e da pastagem. Em termos médios, o ganho de peso

TABELA 1. Freqüência (\%) das espécies herbáceas mais comuns nas parcelas do experimento, no período de 1992-1994'.

\begin{tabular}{|c|c|c|c|c|c|c|c|c|c|}
\hline \multirow[t]{2}{*}{ Espécies } & & \multicolumn{2}{|c|}{$\mathrm{CPA}$} & \multicolumn{2}{|c|}{ CPNA } & \multicolumn{2}{|c|}{ CLA } & \multicolumn{2}{|c|}{ CLNA } \\
\hline & & 1992 & 1994 & 1992 & 1994 & 1992 & 1994 & 1992 & 1994 \\
\hline & & \multicolumn{8}{|c|}{ Gramíneas } \\
\hline Milhã-branca & (Brachiaria plantaginea) & 40,0 & 0,0 & 40,0 & 0,0 & 46,0 & 7,0 & 61,0 & 0,0 \\
\hline Barba-de-bode & (Cyperus compressus) & 33,0 & 0,0 & 23,0 & 8,0 & 35,0 & 2,0 & 20,0 & 2,0 \\
\hline Capim-de-roça & (Digitaria sp.) & 14,0 & 3,0 & 0,0 & 0,0 & 14,0 & 16,0 & 10,0 & 4,0 \\
\hline \multirow[t]{2}{*}{ Rabo-de-raposa } & (Setaria sensitiva) & 0,0 & 0,0 & 0,0 & 1,0 & 27,0 & 6,0 & 16,0 & 2,0 \\
\hline & & \multicolumn{8}{|c|}{ Leguminosas } \\
\hline Feijão-de-rola & (Phaseolus lathiroides) & 40,0 & 36,0 & 44,0 & 47,0 & 47,0 & 65,0 & 53,0 & 49,0 \\
\hline Mata-pasto & (Cassia tora) & 23,0 & 33,0 & 29,0 & 48,0 & 59,0 & 51,0 & 17,0 & 25,0 \\
\hline Amendoim-bravo & (Arachis pusilla) & 21,0 & 0,0 & 24,0 & 0,0 & 21,0 & 3,0 & 25,0 & 14,0 \\
\hline \multirow[t]{2}{*}{ Malícia } & (Mimosa sensitiva) & 18,0 & 0,0 & 12,0 & 0,0 & 0,0 & 7,0 & 28,0 & 18,0 \\
\hline & & \multicolumn{8}{|c|}{ Outras dicotiledôneas } \\
\hline Jitirana-lisa & (Ipomea sp.) & 69,0 & 45,0 & 96,0 & 51,0 & 77,0 & 64,0 & 97,0 & 54,0 \\
\hline Jitirana-peluda & (Merrenia aegyptia) & 58,0 & 34,0 & 95,0 & 19,0 & 80,0 & 41,0 & 98,0 & 9,0 \\
\hline Pacopaco & (Wissadula spicata) & 42,0 & 14,0 & 35,0 & 5,0 & 54,0 & 0,0 & 36,0 & 0,0 \\
\hline Bamburral & (Hyptis suaveolens) & 29,0 & 87,0 & 30,0 & 98,0 & 55,0 & 65,0 & 27,0 & 96,0 \\
\hline Azedinho & (Oxalis sp.) & 34,0 & 0,0 & 28,0 & 0,0 & 39,0 & 0,0 & 29,0 & 0,0 \\
\hline Bredo & (Amaranthus viridis) & 19,0 & 0,0 & 12,0 & 0,0 & 26,0 & 0,0 & 17,0 & 0,0 \\
\hline Evólvulos & (Poligola sp.) & 21,0 & 0,0 & 0,0 & 3,0 & 16,0 & 0,0 & 15,0 & 0,0 \\
\hline Manda-pulão & (Croton sp.) & 16,0 & 0,0 & 14,0 & 0,0 & 19,0 & 0,0 & 11,0 & 0,0 \\
\hline Vass.-de-botão & (Borreria sp.) & 19,0 & 3,0 & 0,0 & 3,0 & 21,0 & 5,0 & 0,0 & 11,0 \\
\hline
\end{tabular}

TABELA 2. Disponibilidade (kg/ha) e composição florística (\%) da fitomassa de pé nas parcelas experimentais.

\begin{tabular}{|c|c|c|c|c|}
\hline \multirow[t]{2}{*}{ Carga $^{1}$} & \multicolumn{2}{|c|}{1992} & \multicolumn{2}{|c|}{1994} \\
\hline & Total & $\%$ gram. & Total & $\%$ gram. \\
\hline CLA & 3169,0 & 23,0 & 4934,3 & 0,0 \\
\hline CPA & 2331,0 & 33,0 & 4248,7 & 0,0 \\
\hline Média & 2750,0 & 28,0 & 4591,5 & 0,0 \\
\hline CLNA & 2037,7 & 13,0 & 3370,9 & 0,0 \\
\hline CPNA & 2091,2 & 16,0 & 3786,4 & 0,0 \\
\hline Média & 2064,5 & 14,5 & 3578,6 & 0,0 \\
\hline Média geral & 2407,2 & 21,2 & 4085,0 & 0,0 \\
\hline
\end{tabular}

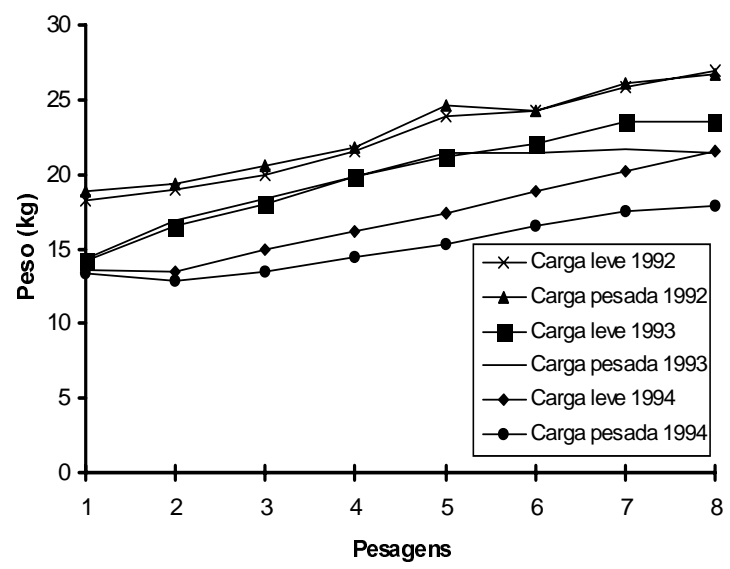

FIG. 1. Desenvolvimento ponderal de ovinos sob duas taxas de lotação em caatinga raleada. 
TABELA3. Médias do ganho de peso vivo diário e por período de ovinos submetidos a pastoreio de curta duração em caatinga raleada ${ }^{1}$.

\begin{tabular}{lcccc}
\hline \multirow{2}{*}{ Ano } & \multicolumn{4}{c}{ Carga animal } \\
\cline { 2 - 5 } & Leve & Pesada & Leve & Pesada \\
\hline 1992 & $------(g / c a b / d i a)$ & --------- & $-26,7 \mathrm{aB}$ & $77,7 \mathrm{aA}$ \\
1993 & $105,4 \mathrm{bA}$ & $102,3 \mathrm{aA}$ & $34,9 \mathrm{aB}$ & $81,9 \mathrm{aA}$ \\
1994 & $132,4 \mathrm{aA}$ & $103,6 \mathrm{aB}$ & $32,6 \mathrm{aB}$ & $54,1 \mathrm{bA}$ \\
\hline Média & $86,6 \mathrm{cA}$ & $47,5 \mathrm{bB}$ & $31,4 \mathrm{~B}$ & $71,2 \mathrm{~A}$ \\
\hline
\end{tabular}

${ }^{1}$ Médias seguidas por letras iguais, minúsculas nas colunas e maiúsculas nas linhas, não diferem entre si $(\mathrm{P}>0,01)$ por contrastes ortogonais.

por cabeça (g/dia) foi superior nas parcelas sob carga leve, enquanto a produção de peso vivo animal por área $(\mathrm{kg} / \mathrm{ha})$ foi maior $(\mathrm{P}<0,01)$ nas áreas sob carga pesada. O maior $(\mathrm{P}<0,01)$ ganho diário foi observado nas parcelas sob carga leve em 1993 (132,4 g), ao passo que o menor, nas parcelas sob carga pesada em 1994 (47,5 g). Esses resultados foram nitidamente superiores aos encontrados por Oliveira et al. (1986) com ovinos. A produção de peso vivo animal por área manteve-se constante nas parcelas sob carga leve $(p>0,05)$, mas decresceu significativamente $(\mathrm{p}<0,05)$ nos piquetes sob carga pesada. A produção de peso vivo por hectare nas áreas de carga pesada foi superior à das áreas de carga leve em todos os anos de execução da pesquisa, com o valor médio de $71,2 \mathrm{~kg} / \mathrm{ha} /$ ano correspondente a quase quatro vezes o encontrado por Leite et al. (1995).

\section{CONCLUSÕES}

1. O pastejo de ovinos promove, a curto prazo, o desaparecimento das gramíneas do estrato herbáceo da caatinga raleada.

2. As leguminosas Arachis pusilla e Mimosa spp. e outras dicotiledôneas herbáceas (Oxalis sp., Amaranthus spp., Croton sp.) têm suas freqüências reduzidas, enquanto o bamburral (Hyptis suaveolens) apresenta aumento em sua ocorrência.

3. O acabamento de ovinos, em pastagem nativa raleada, durante o período chuvoso, em sistema de pastoreio de curta duração apresenta melhor rendimento $(70,0 \mathrm{~kg} / \mathrm{ha})$ com uma carga animal pesada (10 cab./ha).
4. A adubação orgânica não mostra efeitos significantes no desempenho dos animais, durante os três anos de estudo.

5. Apesar da elevada produção animal, o pastejo de curta duração somente com ovinos, não é recomendado no Ceará, por desestabilizar a composição florística do estrato herbáceo, principal componente da dieta desses ruminantes.

\section{REFERÊNCIAS}

ANDREASE, F. Teor de cálcio e fósforo nas pastagens. Informativo Tortuga, São Paulo, v.1, n.4, p.3-19, 1971.

COX, G.M. Laboratory manual of general ecology. Iowa: C. Brown Company Publishers, 1967. 165p.

HEITSCHMIDT, R.K.; FRASURE, J.R.; PRICE, D.L.; RITTENHOUSE, L.R. Short duration grazing at the Texas Experimental Ranch: weight gains of growing heifers. Journal of Range Management, v.35, n.3, p.375-378, May 1982.

HEITSCHMIDT, R.; WALKER, J. Short duration grazing and the Savory Grazing Method in perspective. Rangelands, v.5, n.5, p.147-150, 1983.

LEITE, E.R.; ARAÚJO FILHO, J.A. de; PINTO, F.C. Pastoreio combinado de caprinos com ovinos em caatinga rebaixada: desempenho da pastagem e dos animais Pesquisa Agropecuária Brasileira, Brasilia, v.30, n.8, p.1129-1134, ago. 1995.

MILLER, A. Meteorology. 2.ed.Columbia, Ohio: Charles E. Merril Publishing Company, 1971. 154p. 
NASCIMENTO, A.E. Influência da raça na seleção da dieta por caprinos e ovinos em caatinga nativa e raleada no sertão central cearense. Fortaleza: UFC, 1988. 69p. Tese Mestrado.

OLIVEIRA, E.R. de; BARROS, N.N.; ROBB, T.W.; JOHNSON, W.L.; PANT, K.P. Substituição da torta de algodão por feno de leguminosas em rações baseadas em restolho da cultura do milho para ovinos em confinamento. Pesquisa Agropecuária Brasileira, v.21, n.5, p.555-564, 1986.

PEREIRA FILHO, J.M. Efeitos do pastoreio alternado ovino-caprino sobre a composição florística da vegetação herbácea de uma caatinga raleada. Fortaleza: UFC, 1995. 86p. Tese de Mestrado.
RELATÓRIO TÉCNICO ANUAL DO CENTRO NACIONAL DE PESQUISA DE CAPRINOS, 1982-1986. Sobral: Embrapa-CNPC, 1986. p.39-40.

SILVA, R.N.P. Efeitos da adubação fosfatada e do regime de uso sobre a produção e composição florística do estrato herbáceo de uma caatinga raleada. Fortaleza: UFC, 1992. 113p. Tese de Mestrado.

WEIGEL, J.R.; MCPHERSON, G.R.; BRITTON, C.M. Effects of short-duration grazing on winter annuals in the Texas Rolling Plains. Journal of Range Management, v.42, n.5, p.372-375, Sept. 1989. 